\title{
AGRICULTURAL ENGINEERING BASED ON SYSTEM ANALYSIS AND ELECTRONIC IMAGING
}

\author{
Mohamed Najeh Lakhoua \\ ENICathage, University of Carthage, Tunisia \\ E-mail: MohamedNajeh.Lakhoua@enicarthage.rnu.tn \\ Jamel Ben Salem \\ University of Carthage, Tunisia \\ E-mail: bsj_jamel@yahoo.fr \\ Tahar Battikh \\ University of Tunis, Tunisia \\ E-mail: btahar@yahoo.com \\ Imed Jabri \\ University of Tunis, Tunisia \\ E-mail: imedjabri@yahoo.com
}

Submission: $12 / 7 / 2020$ Revision: $12 / 15 / 2020$ Accept: 1/11/2021

\section{ABSTRACT}

In this paper, we present the need for system analysis and electronic imaging for the study of Agricultural Engineering. In fact, the system analysis aims to structure the analysis of agricultural systems. In fact, we present a literature review of system analysis and the need for electronic imaging. Then, two applications of Agricultural Engineering are presented. In fact, the basic principle of the application of stock management of a grain weighing system is presented. An application of the identification of the behavioral criteria of dairy cattle through electronic imaging is presented. Finally, the different results obtained from these applications are discussed.

Keywords: Agricultural Engineering, system analysis, electronic imaging, weighing system, stock management, dairy cattle 
DOI: 10.14807/ijmp.v12i8.1515

\section{INTRODUCTION}

The Agricultural Engineering field is the engineering of agricultural production and processing. It combines the disciplines of mechanical, civil, electrical, food science and chemical engineering principles with comprehension of agricultural principles according to technological principles (Field, Solie \& Roth, 2007). A key objective of this discipline is to advance the efficiency and sustainability of agricultural practices.

Agricultural engineers may achieve tasks such as planning, supervising and managing the building of dairy effluent schemes, irrigation, drainage, flood water control systems, performing environmental impact assessments, agricultural product processing and interpret research results and implement relevant practices (Brown, 1988).

The first use of Agricultural Engineering was the introduction of irrigation in large level agriculture. The practice would not develop until the industrial revolution.

With the augment of tractors and machines in the industrial revolution, a new age in Agricultural Engineering began. Over the course of the industrial revolution, mechanical harvesters and planters would change field hands in most of the food and cash crop industries. In the 20th century, with the rise in reliable engines were implemented to disperse pesticides. The introduction of these engineering concepts into the field of agriculture allowed for a huge boost in the productivity of crops, dubbed a "second agricultural revolution" (DeForest, 2007).

The integration of an automation and supervision of grain weighing is very central because of the advantages that it presents in terms of clutter, and exploitation suppleness (Bleux, 1998). The monitoring of the weighing system of grains contributes to the development of the storage speed and by optimization in the time of the grain silos handling (Lakhoua, Battikh \& Jabri, 2019; Lakhoua, 2019).

A variety of studies and reflections on the development of the agricultural sector have stressed the importance of upgrading of farms. Exploitation of automated production systems is a actuality especially in the cattle breeders structured at the level of the treaty and complementation food rooms, the use of ICT (information and communications technology) remains shy in Tunisia (Lakhoua, 2013; Lakhoua, 2012).

Certainly, with the expansion of herds and the desire to develop offspring, cows are more covered by bulls but are artificially inseminated after their observation in heat (Jemmali, 2016; Lakhoua, 2009). 
DOI: 10.14807/ijmp.v12i8.1515

In computer science, digital image processing is the use of a digital computer to process digital images through an algorithm. As a subcategory or field of digital signal processing, digital image processing has many advantages over analog image processing (Tillett, 1991). It allows a much wider range of algorithms to be applied to the input data and can avoid problems such as the build-up of noise and distortion during processing. Since images are defined over two dimensions (perhaps more) digital image processing may be modeled in the form of multidimensional systems. The generation and development of digital image processing are largely affected by three factors: first, the development of computers; second, the development of mathematics; third, the demand for a wide range of applications in environment, agriculture, military, industry and medical science has increased (Zhen \& Yang, 2011).

This paper can be heavily divided into six parts: after a presentation of an introduction on Agricultural Engineering, we present the system analysis and electronic imaging. In sections three and four, we present two applications of system analysis and imaging in Agricultural Engineering field. Finally, the last presents conclusion and future work.

\section{PRESENTATION OF SYSTEM ANALYSIS}

The systemic approach, sometimes called systemic analysis, represents a relative interdisciplinary field to the study of objects in their complexity (Cavelery, 1994; Lakhoua, 2018a). It enables to present an object of study in its environment, in its working, in its mechanisms and in what doesn't appear while doing the sum of its parts.

Among the techniques of system analysis (Lakhoua, 2018b), we mention: (1) methods of analysis that enable to systematize and to canalize the various perceptions, (2) specification languages possessing syntax and very definite semantics, and (3) simulation languages.

According to the method and the tool applied, additional parameters can be defined (Lakhoua et al., 2016) (Figure 1). 


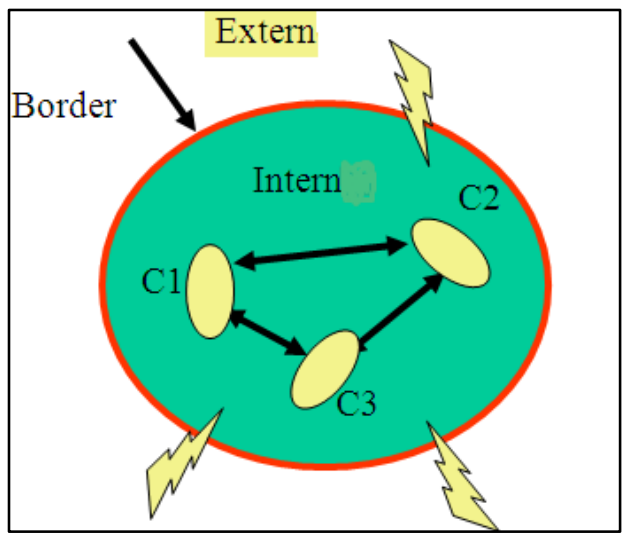

Figure1: Global diagram of a system

The model developed, want to be a complete one; whenever, to validate this model, we applied it to the situation of the agricultural systems. This choice was taken in thought the significance of various management problems and the physical information (Lakhoua, 2012; Lakhoua, 2008).

\section{STUDY OF A WEIGHING SYSTEM IN ORDER TO MANAGE A GRAIN SILO}

The analysis of the weighing system of a grain silo and the study of the stock management is essential in view to develop the existing system. This is why we present in this paper an example of Djebel Djloud grain silo (near to Tunis) which is exploited by the SMCSAGC (Société Mutuelle Centrale des Services Agricoles- Grandes Cultures) and plays a significant role in general in the agricultural sector of the country and in particular in the grain domain (Lakhoua, 2018c).

In fact, the weighing activity is an essential activity in the grain storage process. The device to ensure weighing in the grain storage silo is unique, it is the bridge.

In fact, weighing devices can be categorized into two categories: circuit scale and weighbridge (Lakhoua, Battikh \& Jabri, 2019). These two devices are usually connected to an interface operator for controlling the weighing process whose measurement signal is provided by electronic stress gauge sensors and a printer to edit weighing tickets. In the case of the circuit scale, the measurement signal is provided via an Industrial Programmable.

The weighbridge of our grain silo is constituted of electronic sensors. It enables to do the weighing activities in the entrance and in the exit of grain trucks. This weighing system is ordered by a measuring of load and it is currently connected to a printer allowing the tickets management (Figure 2). 


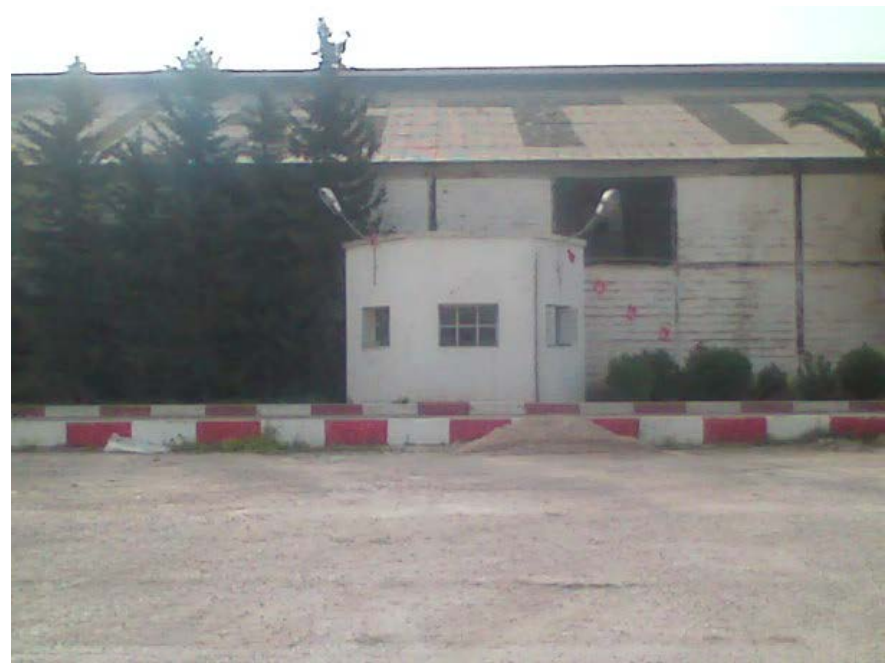

Figure 2: The weighbridge of the grain silo

Since the control and control parameters of a storage device are diversified (weight, temperature, humidity, gas release, level control, aeration...), weighing is the central activity because it controls the flow in entry and exit. In this way, we present the study of the weighing system.

The production management of grain stock consists of at designing, conducting and supervising production and distribution systems (Lakhoua, Balti \& Ettriki, 2013) (Figure 3).

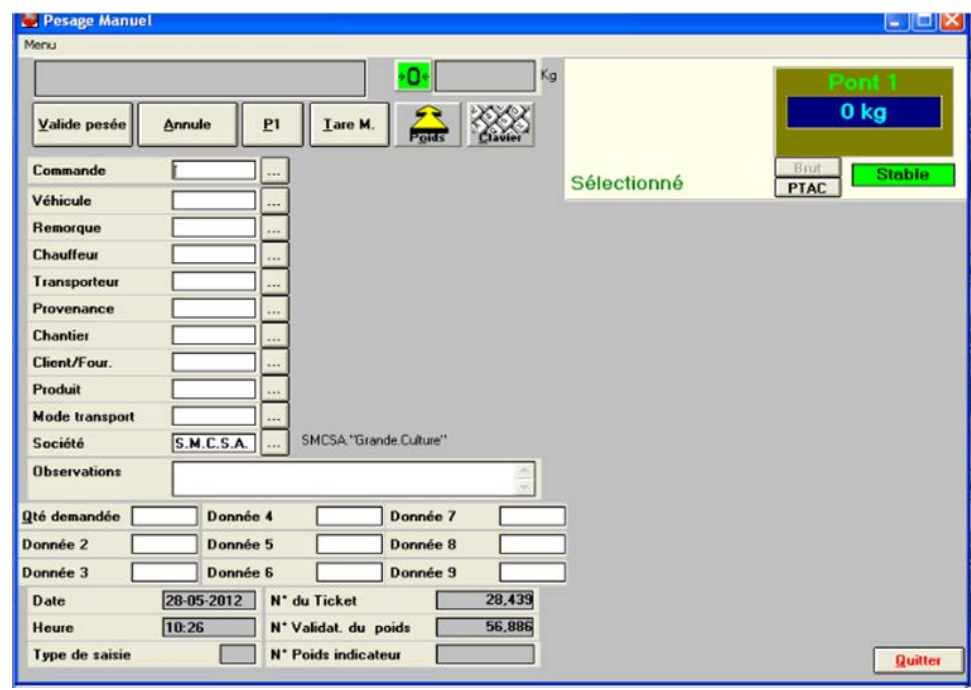

Figure 3: The weighing engineering software

The grain silo management adopted a pragmatic gait on the basis of a case study. The elaborate methodology, the developed tools as well as the gotten results incite us to continue in the objective to develop a strategy of performances assessment of a weighing system of grains and help to the decision.

\section{IDENTIFICATION OF THE BEHAVIORAL CRITERIA OF DAIRY CATTLE ON THE BASIS OF IMAGING}


INDEPENDENT JOURNAL OF MANAGEMENT \& PRODUCTION (IJM\&P)

http://www.ijmp.jor.br

v. 12, n. 8, November-December 2021

ISSN: 2236-269X

DOI: 10.14807/ijmp.v12i8.1515

Various studies and reflections on the development of the agricultural sector have stressed the importance of upgrading of farms. Exploitation of automated production systems is a reality especially in the cattle breeders structured at the level of the Treaty and complementation food rooms, the use of ICT remains shy in Tunisia.

Indeed, with the expansion of herds and the desire to improve offspring, cows are more covered by bulls but are artificially inseminated after their observation in heat (Bouraoui et al., 2002).

The production of milk and meat of a milk cow is directly related to their reproductive function. It is the birth of the newborn that triggers the production of milk in this animal. This birth called calving is direct function of the success of the artificial insemination following accurate detection of the reentry period in heat of the cow in question.

However the heat at farms size detection is often provided by workers and therefore prone to errors of observation. It is the result of a multitude of factors related to the accuracy of the observation of the signs of heat, to the effectiveness of artificial insemination as well as the fertility of the seed. To have a calving every 12 months, $90 \%$ of the cows must go into heat within 60 days after their calving. The interval between calving and fertilising insemination must be on average between 50 and 60 days.

Milk production plays a key role in the agricultural sector and in the Tunisian economy (Hammami, 2004). Since the 1990s, the State encourages investment in the breeding of dairy cows to meet the growing demand for milk and its derivatives. This encouragement enabled Tunisia to achieve self-sufficiency in milk since 1999.

Although the number of livestock has increased significantly and that the existing races in Tunisia, through import, can have very high yields, we're still far from the optimal production rate. This is due mainly to a low detection rate of cows in heat (OEP, 2015).

Farming occupies, in Tunisia, the most important agricultural production part. It represents between $32 \%$ and $37 \%$ of the value of agricultural production with 769 thousand cattle heads, 7 million sheep, 1.5 million goats and 70 thousand units females of camelids.

The livestock sector plays an important socio-economic role. He contributed $22 \%$ of permanent positions in agricultural activities. It affects a total of 112000 cattle producers, 274 000 herders of sheep and 2300 breeders of camels in addition to farms poultry and rabbits.

Three classes of farmers are met, small (75\%), the means and the ranchers. The latter 
DOI: 10.14807/ijmp.v12i8.1515

(20\%) are often advanced in the application of modern breeding methods (parlours, cold to the farm, Artificial Insemination and improved Genetics). As for the dairy cattle industry, it includes a total of 235 milk collection centers and dairy processing units, 43.

Meat production is considered as a by-product of milk and helps to supply a total of 183 slaughterhouses and 20 units of cuts of red meat. It has a tendency to increase in cows of pure breed at the expense of local and cross cows. In 2010, the purebred cows represented 51\%. In 2015, they accounted for 65 percent. The dairy cow in Tunisia has become more specialized.

In developed countries, several technological attempts have been adopted to assist farmers better manage dairy cattle herds based in particular on the use of pedometers. In Tunisia, the breeding of dairy cows continues to pose problems due mainly to a bad heat detection and insemination time opportune (50,60 days after calving). This has led to calving intervals exceeding 14 months.

It is in this context that this work was proposed to identify the criteria of behavior of dairy cattle in a barn through the application of systemic analysis and electronic imaging (Salem et al., 2006).

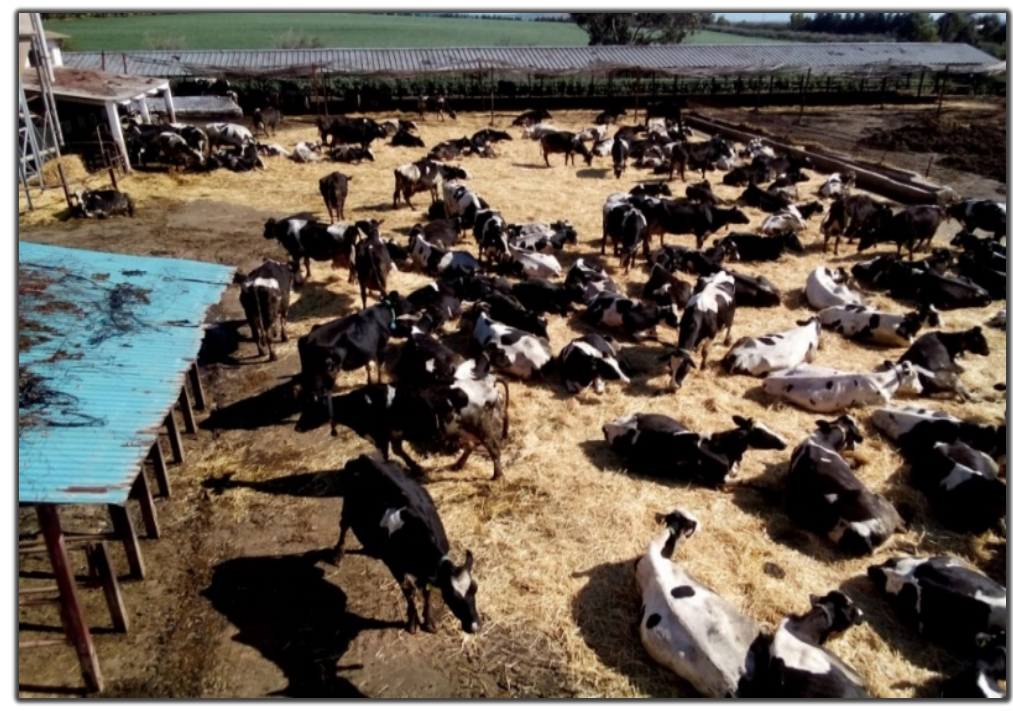

Figure 4: The current barn studied

Figure 5 presents faces detection by the cascad object detector. 
DOI: 10.14807/ijmp.v12i8.1515

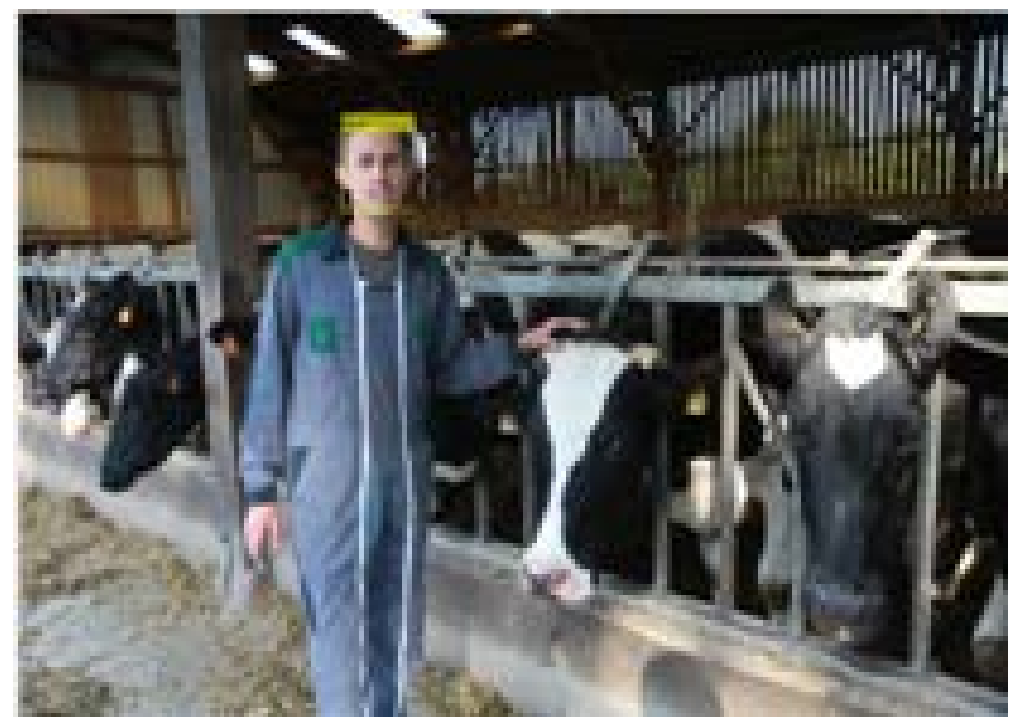

Figure 5: Faces detection by cascad object detector

The dairy cattle sector, like any other agricultural sector in Tunisia, can only develop if appropriate technologies are adopted. Information processing technologies generated in large barns and the application of imaging technologies could strengthen and strengthen the capacity of the agricultural sector in general and in particular the livestock sector.

This work has taken a step forward in a vital area that is agriculture and in particular cattle farming with a spirit of innovation. This breeding that has made our work target is both modern is classic: modern by its new barn and its automatic distribution of food as well as its milking room and classic in the methods of observing cows in heat that depends on the vigilance of workers. The latter is often lacking revealed by the results obtained where only $17 \%$ of the intervals between successive heats are normal, leading to a low heat detection rate (28\%). Heifers did not pose detection problems due to their low numbers

\section{CONCLUSION}

In this paper we presented the need for system approach and electronic imaging for the study of Agricultural Engineering.

Then, we presented a study of two applications of Agricultural Engineering in particular grain silo management and the use of imaging in dairy cattle.

Starting from this study of the need for system analysis and imaging in Agricultural Engineering presented in this paper, we will analysis and model many examples of complex agricultural systems. 
DOI: 10.14807/ijmp.v12i8.1515

\section{REFERENCES}

Bleux, J-M. (1998). Maintenance: Systèmes automatisés de production, Etapes.

Bouraoui, R. et al. (2002). The relationship of temperature-humidity index with milk production of dairy cows in a Mediterranean climate. Animal Research, 51(6), 479-491.

Brown, R. H. (1988). CRC handbook of engineering in agriculture, Boca Raton, FL.: CRC Press.

Cavelery, P. (1994). Soft Systems Thinking: A Pre-condition for Organizational Learning, Human Systems Management, 259-267.

DeForest, S. S. (2007). The vision that cut drugery from farming forever. St. Joseph, Mich.: ASAE.

Field, H. L., Solie, J. B., \& Roth, L. O. (2007). Introduction to agricultural engineering technology: a problem solving approach, New York: Springer.

Jemmali, I. (2016). Observabilité par imagerie électronique d'une étable bovine. Projet de Fin d'Etudes. Ecole Nationale d'Ingénieurs de Carthage, Ferme Ben Chiboub Utique/INAT.

Hammami, H. (2004). Simplification of milk recording in dairy cattle for low input systems. Performance recording of animals. State of the art. 209-214.

Lakhoua, M. N. (2008). Analyse systémique d'un environnement de production en vue d'implanter un système d'information, Thèse, ENIT.

Lakhoua, M. N. (2009). Analysis and Modeling of Industrials Systems in order to develop an Information System, Third International Conference on Research Challenges in Information Science RCIS'09, IEEE, Fes, Morocco.

Lakhoua, M. N. (2012). Investigation on the application of systemic analysis of the cereals stock mobility process, International Journal of Applied Systemic Studies, Inderscience, 4(4), 227-238.

Lakhoua, M. N. (2013). Systemic analysis of an industrial system: case study of a grain silo, Arabian Journal for Science and Engineering, Springer Publishing, 38, 1243-1254.

Lakhoua, M. N. (2018a). The Need for systemic analysis and design methodology of the medical equipments, International Journal of Applied Systemic Studies, Inderscience, ISSN: 1751-0589, 8(1).

Lakhoua, M. N. (2018b). Using System Analysis and Imagery for the Observability of a Dairy Cattle, Jounal of Computer Science and Control Systems, 11(1).

Lakhoua, M. N. (2018c). Developing New Techniques for Analysis and Control of Grain Silos, Journal of Computer Science and Control Systems, 11(2).

Lakhoua, M. N. (2019). Analysis and Management of a Grain Storage System, International Journal of Information Technology and Electrical Engineering, 8(2).

Lakhoua, M. N., Balti, A., \& Ettriki, R. (2013). Functional analysis and Supervision of a weighing system of cereals, Journal of Electrical Engineering, Politechnica Publishing, 13(3).

Lakhoua, M. N., Battikh, T., \& Jabri, I. (2019). Study of a Weighing System in order to Manage a Grain Silo, Journal of Computer Science and Control Systems, 12(2). 
Lakhoua, M. N., Khanchel, F., Laifi, S., \& Khazemi, S. (2016). System analysis of medical equipment for healthcare management, Annals of the Faculty of Engineering Hunedoara, 14 (4), 17.

OEP. (2015). Indicateurs du Secteur de l'Elevage en Tunisie. 2015. Données Sectorielles.

Salem, M. B. et al. (2006). A review of environmental and management factors affecting the reproductive performance of Holstein-Friesian dairy herds in Tunisia. Livestock Research for Rural Development, 18(4), 123-129.

Tillett, R. D. (1991). Image analysis for agricultural processes: a review of potential opportunities, Journal of Agricultural Engineering Research, 50, 247-258.

Zhe, X., \& Yang, N. (2011). Research progress on agronomic parameter estimation based on spectral analysis technology, International Conference on

Advanced Mechatronic Systems, 348-352. 